\title{
鄱阳湖河湖交错带重金属污染对微生物群落与多样性的影响“
}

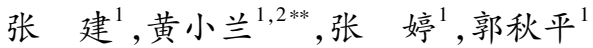 \\ (1: 江西师范大学地理与环境学院,南昌 330022) \\ (2: 江西师范大学鄱阳湖湿地与流域研究教育部重点实验室,南昌 330022)
}

\begin{abstract}
摘 要: 鄱阳湖河湖交错带是鄱阳湖流域内河流生态系统与湖泊生态系统之间的界面区域,该区域物种多样性丰富, 承 接了五大河流的来水, 是重要的污染缓冲区和净化区. 本文研究了鄱阳湖河湖交错带重金属污染对微生物群落结构和微 生物多样性的影响, 结果表明, 已测的重金属 (采、铜、锌、铅和镉) 均有不同程度的污染, 其中, 铅、永污染最严重, 水质标 准为 IV 类以上,其他重金属均为 II 类; 高通量测序结果表明, 鄱阳湖河湖交错带微生物群落主要有变形菌门、放线菌门、 拟杆菌门和疮微菌门 4 类, 平均含量分别为 $58.31 \% 、 13.63 \% 、 9.69 \%$ 和 $1.33 \%$. 多样性指数分析结果表明, 昌江与乐安河交 汇处 (R9 点位) 与鄱阳湖出长江口 (H11 点位) 的微生物多样性指数 (Chao 1、Shannon 和 Simpson 指数) 最高, 万家桥 (N2 点位) 与赣江人湖口 (W6 点位) 微生物多样性指数最低. 研究表明, 受重金属污染严重的区域通常会使微生物群落丰度降 低, 然而 R9 和 H11 点位重金属污染严重, 但微生物多样性却较丰富, 说明微生物多样性不仅仅受单一因子影响, 而是多 重因子共同影响.
\end{abstract}

关键词: 鄱阳湖; 河湖交错带; 重金属;微生物群落

\section{Effects of heavy metal pollution on microbial community and diversity in lake-river ecotone of Lake Poyang}

\author{
ZHANG Jian $^{1}$, HUANG Xiaolan ${ }^{1,2 * *}$, ZHANG Ting $^{1}$ \& GUO Qiuping ${ }^{1}$ \\ (1: School of Geography and Environment, Jiangxi Normal University, Nanchang 330022, P.R. China) \\ (2: Key Laboratory of Lake Poyang Wetland and Watershed Research, Ministry of Education, Jiangxi Normal University, Nan- \\ chang 330022, P.R.China)
}

\begin{abstract}
The lake-river ecotone of Lake Poyang is an interfacial area between lake ecosystem and river ecosystem in Lake Poyang basin. The region is rich in species diversity, and it is an important buffer and purification zone of pollution, because the water is coming from the five major rivers. This paper analyzed the effect of heavy metal pollution on the microbial community structure and diversity in lake-river ecotone of Lake Poyang. Moreover, the heavy metals have been measured by atomic absorption spectrometry and atomic fluorescence spectrometry. Our results show that these trace metals ( $\mathrm{Hg}, \mathrm{Cu}, \mathrm{Zn}, \mathrm{Pb}$ and $\mathrm{Cd})$ exhibited different degrees of pollution and the pollution of lead and mercury were the most serious. The concentrations of $\mathrm{Pb}$ and $\mathrm{Hg}$ reached IV in quality standard for ground water, the others reached II. High throughput sequencing results show that the microbial communities were mainly composed of 4 categories: Proteobacteria, Actinobacteria, Bacteriodetes and Verrucomicrobia, the average abundance were $58.31 \%, 13.63 \%, 9.69 \%$ and $1.33 \%$ in lake-river ecotone of Lake Poyang, respectively. The results of diversity index analysis show that, the index (Chao 1, Shannon and Simpson indexes) of R9 site (the interchange between Changiang River and Lean River) and H11 site (the estuary of Lake Poyang flows to Yangtze River) was the highest, the index of N2 site (Wanjiaqiao) and W6 site ( the estuary of the Ganjiang River flows into Lake Poyang) was the lowest. This study shows that microbial community abundance decreased in those badly-contaminated areas. The heavy metal pollution in R9 and H11 sites were serious, but the microbial diversity was rich, suggesting that the factors affecting the microbial diversity were multiple.
\end{abstract}

Keywords: Lake Poyang; lake-river ecotone; heavy metal; microbial community

* 国家自然科学基金项目(41561002)资助. 2017-05-09 收稿;2017-09-11 收修改稿. 张建 (1991 ), 男, 硕士研究 生;E-mail: zhangjian326385@163.com.

** 通信作者;E-mail: huangxiaolanlan@163.com. 
鄱阳湖是长江中下游典型的季节性湖泊, 是我国最大的淡水湖泊,也是国际重要湿地和世界重要的候 鸟栖息地. 该湖位于江西省北部,承接了省内五大河流 (赣江、抚河、信江、饶河和修河) 来水,在维系鄱阳湖 流域生态平衡和生物多样性方面有着重要的作用. 河湖交错带是指河流生态系统与湖泊生态系统之间的界 面区 ${ }^{[1]}$. 它在河水与湖水混合的区域内形成一个具有潜在陡峭环境梯度的动态区, 与邻近的河流生态系统 或湖泊生态系统相比较, 河湖交错带具有更加丰富的物种多样性, 是一个重要的污染水净化区和污染缓冲 区 $^{[2]}$. 鄱阳湖河湖交错带是整个鄱阳湖流域内河流生态系统与鄱阳湖生态系统之间的交错混合区域, 它受 鄱阳湖与五大河流两岸人类活动以及五大河流与鄱阳湖之间相互作用等的影响, 对区域经济发展和生态安 全有着重要作用.

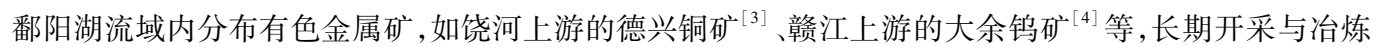
生产的“三废”不仅对矿区生态环境及人类生存产生了影响,而且污染物通过河流汇人鄱阳湖,大部分重金 属不易被微生物降解吸收, 鄱阳湖流域生态环境也因此易遭受破坏. 微生物群落通过吸附、淋滤及转化等影 响环境中的重金属活性 ${ }^{[5]}$, 同样在重金属胁迫下, 可降低微生物群落的活性, 污染严重时还会降低微生物生 物量, 影响微生物的生理生化功能, 最终影响环境有机质的降解 ${ }^{[6]}$, 二者相互作用研究已引起研究者的广泛 关注, 为了保持鄱阳湖 “青山常青, 绿水常绿”, 研究重金属污染与微生物群落的相互作用尤为迫切. 随着分 子生物学技术的发展, 研究各种环境下微生物群落的特征已经日益完善, 刘晋仙等 ${ }^{[7]}$ 利用高通量测序技术 发现山西中条山十八河铜尾矿区水体中微生物有 8 个优势科 (鞘脂单胞菌科、柄杆菌科、甲基杆菌科、类诺 卡氏菌科、微杆菌科、微球菌科、链球菌科和类芽狍杆菌科) 的相对丰度与重金属浓度存在显著相关关系. Zhao 等 ${ }^{[8]}$ 利用变性梯度凝胶电泳 (denatured gradient gel electrophoresis, DGGE) 技术发现重金属污染物能抑 制微生物的生长, 只有少量具有较强抗性的微生物能存活. 重金属污染对鄱阳湖微生物群落特征的影响目 前研究尚少, 为此, 本文在检测鄱阳湖河湖交错带水体重金属浓度的基础上,利用 Miseq 平台高通量测序技 术分析微生物群落结构及多样性特征, 并寻找重金属浓度与微生物多样性之间的联系, 探讨重金属污染对 微生物多样性的影响, 以期加深认识河湖交错带微生物在湖泊生态系统和河流生态系统中的功能与地位.

\section{1 材料与方法}

\section{1 采样点分布}

在查阅文献及野外调研的基础上,确定了河湖交错带的采样范围, 考虑到丰水期存在对重金属的稀释 作用, 选择在枯水期进行水样采集. 采集时利用手持 GPS 定位仪记录采样点的地理坐标, 使用电子 $\mathrm{pH}$ 仪测 定实时的水温以及 $\mathrm{pH}$ 值. 利用 ArcGIS 软件绘制采样点分布图 (图 1).

\section{2 样品采集和预处理}

每个采样点采集 $2 \mathrm{~L}$ 水样, 装人已灭菌聚乙烯瓶中, 低温保存, 在实验室无菌环境下过滤. 每个样品都必 须经过 0.85 和 $0.22 \mu \mathrm{m}$ 孔径的滤膜过滤两次, 把 $0.22 \mu \mathrm{m}$ 孔径的滤膜放人离心管, 之后放在 $-80^{\circ} \mathrm{C}$ 冰箱保存, 用于测定样品中的 DNA. 同时每个样点采集 $500 \mathrm{ml}$ 水样用于重金属浓度的测定, 由于地表水中重金属浓度 一般较低,所以需要预先浓缩处理,之后再进一步测定.

\section{3 样品相关测定方法}

1.3.1 微生物多样性指数测定 将预处理好的样品送到上海美吉生物医药科技有限公司进行 Miseq 平台 $16 \mathrm{~S}$ $\mathrm{rRNA}$ 测序, 所用引物为 338F (ACTCCTACGGGAGGCAGCAG) 和 806R (GGACTACHVGGGTWTCTAAT), 利用 $2 \%$ 琼脂糖凝胶电泳检测 PCR 产物.

1.3.2 重金属浓度测定铜 $(\mathrm{Cu})$ 、锌 $(\mathrm{Zn}) 、$ 、铅 $(\mathrm{Pb})$ 、镉 $(\mathrm{Cd})$ 的浓度依据国家标准要求的原子吸收分光光度 法测定 (GB/T 7475-1987). 采 $(\mathrm{Hg})$ 浓度依据国家水利行业标准要求的原子苂光光度法测定 (SL 327.22005).

\section{4 数据处理及统计分析}

通过 Miseq 测序平台对原始数据进行过滤处理, 得到优化序列, 然后进行 OTU 聚类分析, 基于聚类分析 结果,利用 Mothur 软件对 $97 \%$ 相似水平的 OTU 作多样性指数分析. 群落结构分布基于测序结果利用 Excel 软件作图,PCA 分析和 Pearson 分析利用 SPSS 软件完成, 兄余分析利用 Canoco 4.5 软件完成. 


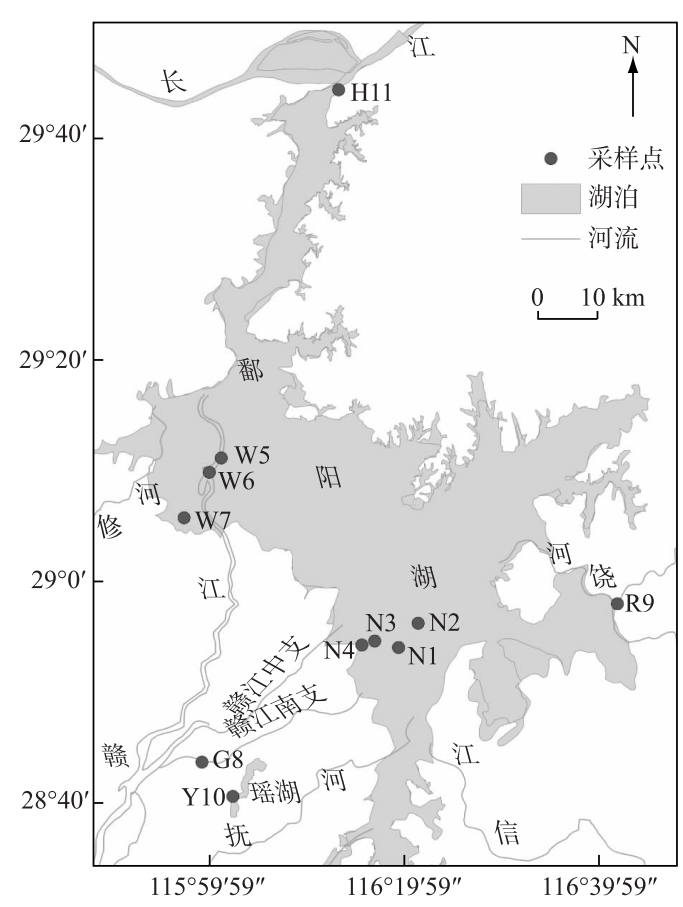

图 1 采样点分布

Fig.1 Distribution of sampling sites

\section{2 结果与分析}

\section{1 重金属浓度分析}

鄱阳湖河湖交错带各样点表层水温差异较大, 平均水温为 $11.5^{\circ} \mathrm{C}$, 水温最高为 $13^{\circ} \mathrm{C}$, 而最低只有 $9^{\circ} \mathrm{C}$. 水体 $\mathrm{pH}$ 值差异较小, 平均为 6.76 , 只有 W5 和 $\mathrm{H} 11$ 点位大于 7 , 其他点位均在平均值左右 (表 1 ). 各点位表 层水体重金属浓度有明显差别: $\mathrm{Hg}$ 浓度在 $\mathrm{N} 3$ 点位 $\left(6.5 \times 10^{-4} \mathrm{mg} / \mathrm{L}\right)$ 最高, 在 W6 和 W7 点位 $\left(5.2 \times 10^{-4} \mathrm{mg} / \mathrm{L}\right)$ 最低; $\mathrm{Cu}$ 浓度在 $\mathrm{H} 11$ 点位 $(0.14 \mathrm{mg} / \mathrm{L})$ 最高, 在 $\mathrm{N} 1$ 和 $\mathrm{N} 3$ 点位 $(0.04 \mathrm{mg} / \mathrm{L})$ 最低; $\mathrm{Zn}$ 浓度在 W5 点位 $(0.47$

表 1 鄱阳湖河湖交错带表层水体的物理性质

Tab.1 Physical characteristics of surface water in lake-river ecotone of Lake Poyang

\begin{tabular}{|c|c|c|c|c|c|}
\hline 点位 & 地点名称 & 纬度 & 经度 & 水温 $/{ }^{\circ} \mathrm{C}$ & $\mathrm{pH}$ \\
\hline N1 & 矶山 & $28^{\circ} 54^{\prime} 12.55^{\prime \prime} \mathrm{N}$ & $116^{\circ} 19^{\prime} 15.16^{\prime \prime} \mathrm{E}$ & 12 & 6.45 \\
\hline $\mathrm{N} 2$ & 万家桥 & $28^{\circ} 56^{\prime} 24.26^{\prime \prime} \mathrm{N}$ & $116^{\circ} 21^{\prime} 14.69^{\prime \prime} \mathrm{E}$ & 13 & 6.63 \\
\hline N3 & 常湖 & $28^{\circ} 54^{\prime} 46.70^{\prime \prime} \mathrm{N}$ & $116^{\circ} 16^{\prime} 48.11^{\prime \prime} \mathrm{E}$ & 11 & 6.79 \\
\hline N4 & 南矶大桥 & $28^{\circ} 54^{\prime} 25.03^{\prime \prime} \mathrm{N}$ & $116^{\circ} 15^{\prime} 29.00^{\prime \prime} \mathrm{E}$ & 13 & 6.92 \\
\hline W5 & 望湖亭 & $29^{\circ} 11^{\prime} 22.26^{\prime \prime} \mathrm{N}$ & $116^{\circ} 00^{\prime} 50.40^{\prime \prime} \mathrm{E}$ & 13 & 7.03 \\
\hline W6 & 赣江人湖口 & $29^{\circ} 11^{\prime} 12.32^{\prime \prime} \mathrm{N}$ & $116^{\circ} 00^{\prime} 53.86^{\prime \prime} \mathrm{E}$ & 12 & 6.53 \\
\hline W7 & 大湖池观鸟亭 & $29^{\circ} 05^{\prime} 46.30^{\prime \prime} \mathrm{N}$ & $115^{\circ} 57^{\prime} 07.68^{\prime \prime} \mathrm{E}$ & 11 & 6.62 \\
\hline G8 & 富大有路 ( 堤) & $28^{\circ} 43^{\prime} 44.19^{\prime \prime} \mathrm{N}$ & $115^{\circ} 59^{\prime} 11.06^{\prime \prime} \mathrm{E}$ & 12 & 6.74 \\
\hline R9 & 饶河 (昌江与乐安河交汇处) & $28^{\circ} 58^{\prime} 14.14^{\prime \prime} \mathrm{N}$ & $116^{\circ} 41^{\prime} 41.87^{\prime \prime} \mathrm{E}$ & 11 & 6.68 \\
\hline $\mathrm{Y} 10$ & 瑶湖 & $28^{\circ} 40^{\prime} 39.75^{\prime \prime} \mathrm{N}$ & $116^{\circ} 02^{\prime} 22.28^{\prime \prime} \mathrm{E}$ & 10 & 6.87 \\
\hline H11 & 湖口 (鄱阳湖出长江口) & $29^{\circ} 44^{\prime} 31.48^{\prime \prime} \mathrm{N}$ & $116^{\circ} 12^{\prime} 42.78^{\prime \prime} \mathrm{E}$ & 9 & 7.05 \\
\hline
\end{tabular}


$\mathrm{mg} / \mathrm{L})$ 最高, 在 $\mathrm{N} 3$ 点位 $(0.34 \mathrm{mg} / \mathrm{L})$ 最低; $\mathrm{Pb}$ 浓度在 $\mathrm{R} 9$ 点位 $(0.08 \mathrm{mg} / \mathrm{L})$ 最高, 在 W5 点位 $(0.05 \mathrm{mg} / \mathrm{L})$ 最 低; Cd 浓度在 W7 点位 $\left(4.9 \times 10^{-3} \mathrm{mg} / \mathrm{L}\right)$ 最高, 在 $\mathrm{G} 8$ 点位 $\left(3.9 \times 10^{-3} \mathrm{mg} / \mathrm{L}\right)$ 最低. $\mathrm{Hg} 、 \mathrm{Cu} 、 \mathrm{Zn} 、 \mathrm{~Pb}$ 和 $\mathrm{Cd}$ 的平均 浓度分别为 $5.9 \times 10^{-4} 、 0.09 、 0.41 、 0.06$ 和 $4.5 \times 10^{-3} \mathrm{mg} / \mathrm{L}$. 与我国《地表水环境质量标准》(GB 3838-2002) 相 比, $\mathrm{Hg}$ 浓度为 $\mathrm{IV}$ 类标准; $\mathrm{Cu}$ 和 $\mathrm{Zn}$ 浓度均为 II 类标准; $\mathrm{Pb}$ 浓度为 $\mathrm{V}$ 类标准; $\mathrm{Cd}$ 浓度为 II 类标准. 可见 $\mathrm{Pb} 、 \mathrm{Hg}$ 污染比较严重( 表 2).

表 2 鄱阳湖河湖交错带表层水体重金属浓度 $(\mathrm{mg} / \mathrm{L}) *$

Tab.2 Heavy metal concentrations of surface water in lake-river ecotone of Lake Poyang $(\mathrm{mg} / \mathrm{L})$

\begin{tabular}{cccccc}
\hline 点位 & $\mathrm{Hg}$ & $\mathrm{Cu}$ & $\mathrm{Zn}$ & $\mathrm{Pb}$ & $\mathrm{Cd}$ \\
\hline $\mathrm{N} 1$ & $6.0 \times 10^{-4}$ & 0.04 & 0.40 & 0.07 & $4.3 \times 10^{-3}$ \\
$\mathrm{~N} 2$ & $6.2 \times 10^{-4}$ & 0.07 & 0.37 & 0.06 & $4.6 \times 10^{-3}$ \\
$\mathrm{~N} 3$ & $6.5 \times 10^{-4}$ & 0.04 & 0.34 & 0.06 & $4.5 \times 10^{-3}$ \\
$\mathrm{~N} 4$ & $6.4 \times 10^{-4}$ & 0.10 & 0.44 & 0.07 & $4.7 \times 10^{-3}$ \\
$\mathrm{~W} 5$ & $5.9 \times 10^{-4}$ & 0.08 & 0.47 & 0.05 & $4.9 \times 10^{-3}$ \\
$\mathrm{~W} 6$ & $5.2 \times 10^{-4}$ & 0.09 & 0.43 & 0.06 & $4.8 \times 10^{-3}$ \\
W7 & $5.2 \times 10^{-4}$ & 0.09 & 0.39 & 0.06 & $4.9 \times 10^{-3}$ \\
G8 & $6.2 \times 10^{-4}$ & 0.11 & 0.43 & 0.06 & $3.9 \times 10^{-3}$ \\
R9 & $5.6 \times 10^{-4}$ & 0.11 & 0.41 & 0.08 & $4.8 \times 10^{-3}$ \\
Y10 & $6.3 \times 10^{-4}$ & 0.08 & 0.41 & 0.07 & $4.3 \times 10^{-3}$ \\
H11 & $5.9 \times 10^{-4}$ & 0.14 & 0.40 & 0.06 & $4.2 \times 10^{-3}$ \\
I 类标准 & $\leqslant 0.5 \times 10^{-4}$ & $\leqslant 0.01$ & $\leqslant 0.05$ & $\leqslant 0.01$ & $\leqslant 1.0 \times 10^{-3}$ \\
II 类标准 & $\leqslant 0.5 \times 10^{-4}$ & $\leqslant 1.0$ & $\leqslant 1.0$ & $\leqslant 0.01$ & $\leqslant 5.0 \times 10^{-3}$ \\
III类标准 & $\leqslant 1.0 \times 10^{-4}$ & $\leqslant 1.0$ & $\leqslant 1.0$ & $\leqslant 0.05$ & $\leqslant 5.0 \times 10^{-3}$ \\
IV 类标准 & $\leqslant 10.0 \times 10^{-4}$ & $\leqslant 1.0$ & $\leqslant 2.0$ & $\leqslant 0.05$ & $\leqslant 5.0 \times 10^{-3}$ \\
V 类标准 & $\leqslant 10.0 \times 10^{-4}$ & $\leqslant 1.0$ & $\leqslant 2.0$ & $\leqslant 0.1$ & $\leqslant 10.0 \times 10^{-3}$ \\
\hline
\end{tabular}

* 标准数据来自《地表水环境质量标准》( GB 3838-2002).

\section{2 多样性指数分析}

利用 Miseq 测序技术研究鄱阳湖河湖交错带表层水体微生物多样性, 共检测到有效序列数 351830 条, 平均每个样品 31985 条, 序列平均长度为 $445.49 \mathrm{bp}$, 覆盖率为 $99.93 \%$ (图 2). 当 Rarefaction 曲线趋向平坦 时, 说明测序数据量合理, 更多的数据量只会产生少量新的 OTU.

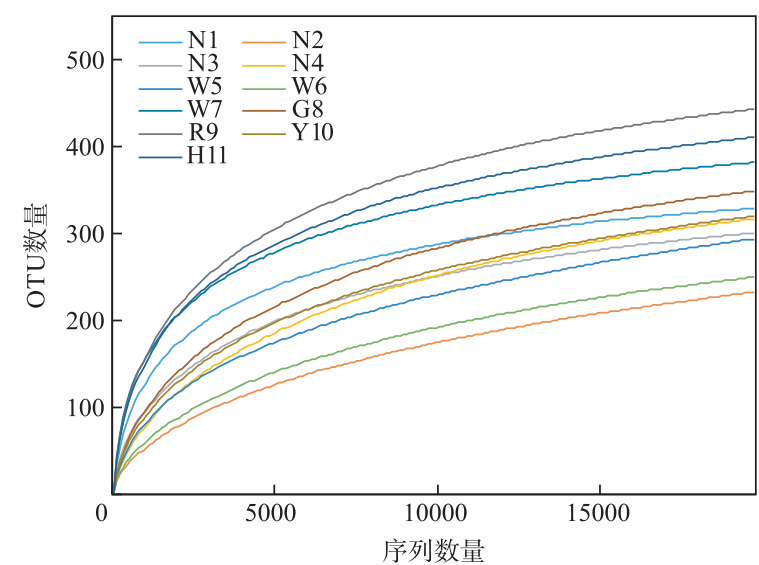

图 2 鄱阳湖河湖交错带表层水体微生物 DNA 序列的 Rarefaction 曲线和 OTU 数量关系

Fig.2 Rarefaction curves of OTUs clustered at 97\% 16S rRNA sequence identity across surface water in lake-river ecotone of Lake Poyang 
鄱阳湖河湖交错带表层水体共检测到 OTU 数量 3618 个,其中 R9 和 H11 点位的 OTU 数量最多, N2 和 W6 点位最少 (表 3). 各样本的 Coverage 指数均在 0.99 以上, 说明本次测序结果代表了样本中微生物的真实 情况. Chao 1 指数和 Shannon 指数都是 R9 点位 $(508.80,3.92)$ 和 H11 点位 $(470.00,3.89)$ 较高, N2 点位 $(353.42,2.12)$ 和 W6 点位 $(320.40,2.19)$ 较低, 这说明 R9 和 H11 点位的微生物多样性相对较高, N2 和 W6 点位的微生物多样性较低. 而 R9 和 H11 点位的 Simpson 指数最低, N2 和 W6 点位的 Simpson 指数最高, 也 证实了这一点 (表 3).

表 3 鄱阳湖河湖交错带表层水体微生物多样性指数

Tab.3 Microbial diversity indices in lake-river ecotone of Lake Poyang

\begin{tabular}{ccccccc}
\hline 点位 & OUT 数量 & 观察到的种数 & Chao 1 指数 & Shannon 指数 & Simpson 指数 & Coverage 指数 \\
\hline N1 & 328 & 245 & 355.13 & 3.28 & 0.12 & 0.997 \\
N2 & 232 & 182 & 353.42 & 2.12 & 0.22 & 0.995 \\
N3 & 300 & 224 & 360.61 & 2.91 & 0.15 & 0.996 \\
N4 & 316 & 237 & 400.25 & 2.39 & 0.21 & 0.995 \\
W5 & 293 & 236 & 453.59 & 2.45 & 0.20 & 0.995 \\
W6 & 249 & 194 & 320.40 & 2.19 & 0.22 & 0.996 \\
W7 & 381 & 278 & 435.24 & 3.94 & 0.07 & 0.997 \\
G8 & 348 & 263 & 429.68 & 2.67 & 0.18 & 0.995 \\
R9 & 442 & 320 & 508.80 & 3.92 & 0.07 & 0.996 \\
Y10 & 319 & 241 & 414.07 & 2.69 & 0.17 & 0.995 \\
H11 & 410 & 305 & 470.00 & 3.89 & 0.06 & 0.996 \\
\hline
\end{tabular}

\section{3 微生物群落结构组成}

鄱阳湖河湖交错带表层水体微生物主要包括: 变形菌门 ( Proteobacteria, 35.68\% 87.00\%), 平均含量为 $58.31 \%$; 放线菌门 (Actinobacteria, $5.61 \% \sim 22.78 \%$ ), 平均含量为 $13.63 \%$; 拟杆菌门 ( Bacteroidetes, $1.84 \%$ $26.44 \%$ ), 平均含量为 $9.69 \%$; 疮微菌门 (Verrucomicrobia, $0.23 \% \sim 7.43 \%$ ), 平均含量为 $1.33 \%$. 所以鄱阳湖河 湖交错带表层水环境的优势菌主要是变形菌门和放线菌门. 超过一半的样本变形菌门含量为 $50 \%$ 以上, 含 量最高的是 N2 点位 $(87.00 \%)$, 最低的是 W7 点位 (35.68\%). 放线菌门含量最高的是 G8 点位 $(22.78 \%)$, 最 低的是 W6 点位 $(5.61 \%), \mathrm{G} 8$ 点位的放线菌门含量是 W6 点位的 4 倍多. 拟杆菌门含量差异非常显著, 最低 为 $1.84 \%$ ( $\mathrm{N} 2$ 点位), 而最高达到 $26.44 \%$ ( $\mathrm{H} 11$ 点位). 而疮微菌门含量总体差异不大, 基本都小于 $1 \%$, 只有 $\mathrm{R} 9$ 点位 (7.43\%) 和 W7 点位 (2.00\%) 两个样本超过了 1\% (图 3), 这与两地的污染情况有关. PCA 分析结果 (图 4) 表明, H11 点位离其他采样点非常远, R9 和 W7 点位距离次之, 说明 H11、R9 和 W7 点位污染严重, 特 别是 $\mathrm{H} 11$ 点位.

除了上述 4 种优势菌门外, OTU 平均相对丰度大于 0.1 的还有 Saccharibacteria $(0 \sim 2.11 \%)$ 、厚壁菌门 ( Firmicutes, $0 \sim 3.79 \%$ )、绿弯菌门 (Chloroflexi, $0 \sim 1.21 \%$ )、Cloacimonetes ( $0 \sim 2.10 \%$ )、梭杆菌门 ( Fusobacteria, 0 $0.43 \%$ ) 和硝化螺旋菌门 ( Nitrospirae, $0.03 \% \sim 0.27 \%$ ).

\section{4 重金属对微生物多样性的影响}

从微生物多样性指数与重金属浓度之间的 Pearson 相关性可见, Cu 浓度与 Chao 1 指数在 0.05 水平 (双 侧)上呈显著正相关;而其他重金属浓度与各个微生物的多样性指数都没有显著相关性(表 4).

从微生物多样性与水体相关物理性质的 Pearson 相关性分析发现, 水温与 OTU 数量、Shannon 指数和 Simpson 指数在 0.05 水平 (双侧) 上显著相关, 其中与 OTU 数量和 Shannon 指数呈负相关, 与 Simpson 指数呈 正相关 (表 5). 水温升高一定程度上会导致微生物数量下降,水温是影响微生物多样性的一个关键因素.

为了更好地考察重金属浓度对微生物群落结构的影响, 以重金属浓度作为环境变量, 微生物门水平数 据作为物种变量做冗余分析 (图 5), 其中轴 1 解释了 $23.2 \%$ 的环境变量, 轴 2 解释了 $12.5 \%$ 的环境变量. 结 果表明, Cu 浓度与 Nitrospirae、TA06、Proteobacteria、Actinobacteria、Firmicutes、Chlamydiae、Bacteroidetes、Parcubacteria 和 Saccharibacteria 等呈正相关, 与 Nitrospirae 和 TA06 的相关性显著, 与 Fusobacteria 呈显著负相 


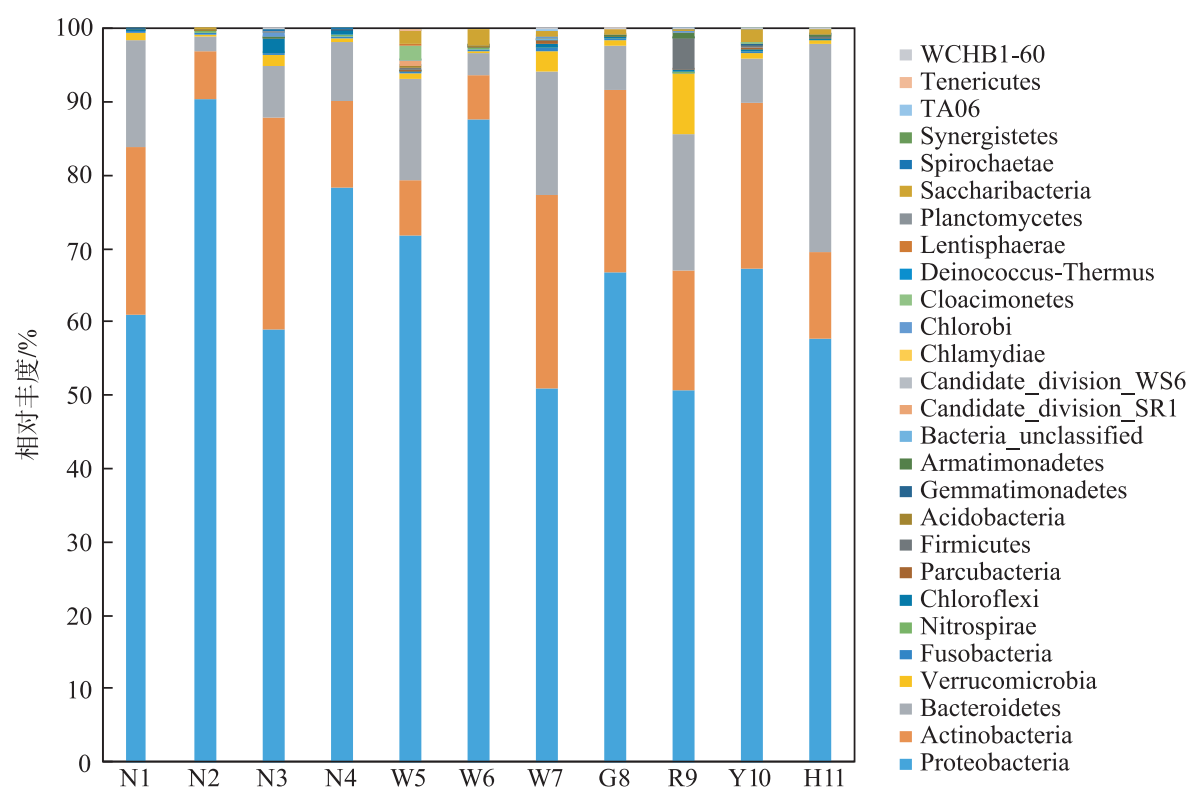

图 3 鄱阳湖河湖交错带表层水体微生物群落结构 (门分类水平)

Fig.3 Microbial community structure at phylum level in lake-river ecotone of Lake Poyang

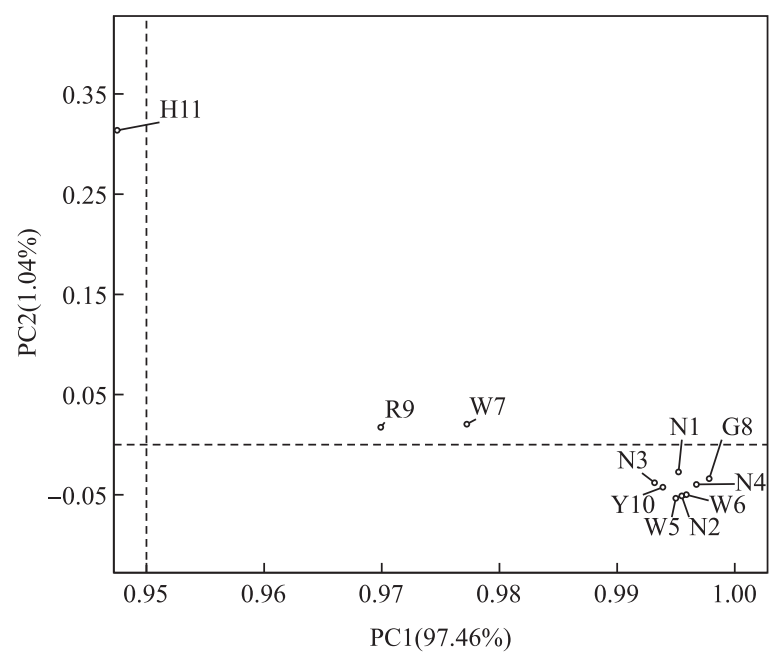

图 4 鄱阳湖河湖交错带表层水体微生物群落的主成分分析

Fig.4 Principal component analysis (PCA) of bacterial community in lake-river ecotone of Lake Poyang

关; Cd 和 Zn 浓度与 Bacteria_unclassified、Saccharibacteria、Tenericutes、Candidate、Lentisphaerae、Synergistetes、 Cloacimonetes 等呈正相关, 与 Bacteria_unclassified 和 Saccharibacteria 的相关性显著, 与 Chloroflexi 和 Spirochaetae 呈显著负相关; $\mathrm{Hg}$ 浓度与 Fusobacteria 呈显著正相关, 与 Nitrospirae 和 TA06 呈显著负相关; $\mathrm{Pb}$ 浓度 与 Chloroflexi 呈显著正相关, 与 Tenericutes、Candidate 和 Bacteria_unclassified 呈显著负相关. 这表明各种微 生物对不同的重金属污染有一定的承受力, 如 Nitrospirae、TA06、Proteobacteria、Acidobacteria、Firmicutes、 Chlamydiae、Bacteroidetes、Parcubacteria、Saccharibacteria 等对 $\mathrm{Cu}$ 污染有一定的承受力, 而 Fusobacteria 对 Cu 污染有指示作用. 
表 4 鄱阳湖河湖交错带表层水体微生物多样性指数与重金属浓度的 Pearson 相关分析 $(n=11)$

Tab.4 Pearson correlation analysis among microbial diversity index and heavy metal concentrations in lake-river ecotone of Lake Poyang $(n=11)$

\begin{tabular}{cccccr}
\hline & $\mathrm{Hg}$ & $\mathrm{Cu}$ & $\mathrm{Zn}$ & $\mathrm{Pb}$ & $\mathrm{Cd}$ \\
\hline OUT 数量 & -0.21 & 0.52 & -0.01 & 0.28 & -0.13 \\
Chao 1 & -0.12 & $0.62^{*}$ & 0.28 & 0.08 & 0.01 \\
Shannon 指数 & -0.34 & 0.25 & -0.27 & 0.09 & -0.01 \\
Ace 指数 & -0.11 & 0.55 & 0.37 & -0.17 & 0.12 \\
Simpson 指数 & 0.31 & -0.27 & 0.32 & -0.09 & 0.05 \\
\hline
\end{tabular}

* 表示在 0.05 水平 (双侧) 上显著相关.

表 5 鄱阳湖河湖交错带表层水体微生物多样性与水体物理性质的 Pearson 相关性 $(n=11)$

Tab.5 Pearson correlation analysis among microbial diversity index and physical characteristics of water in lake-river ecotone of Lake Poyang $(n=11)$

\begin{tabular}{cccccc}
\hline & OUT 数量 & Chao1 & Shannon 指数 & Ace 指数 & Simpson 指数 \\
\hline 水温 & $-0.61^{*}$ & -0.39 & $-0.68^{*}$ & -0.09 & $0.72^{*}$ \\
$\mathrm{pH}$ & 0.19 & 0.53 & -0.07 & 0.53 & 0.00 \\
\hline
\end{tabular}

* 表示在 0.05 水平 (双侧) 上显著相关.

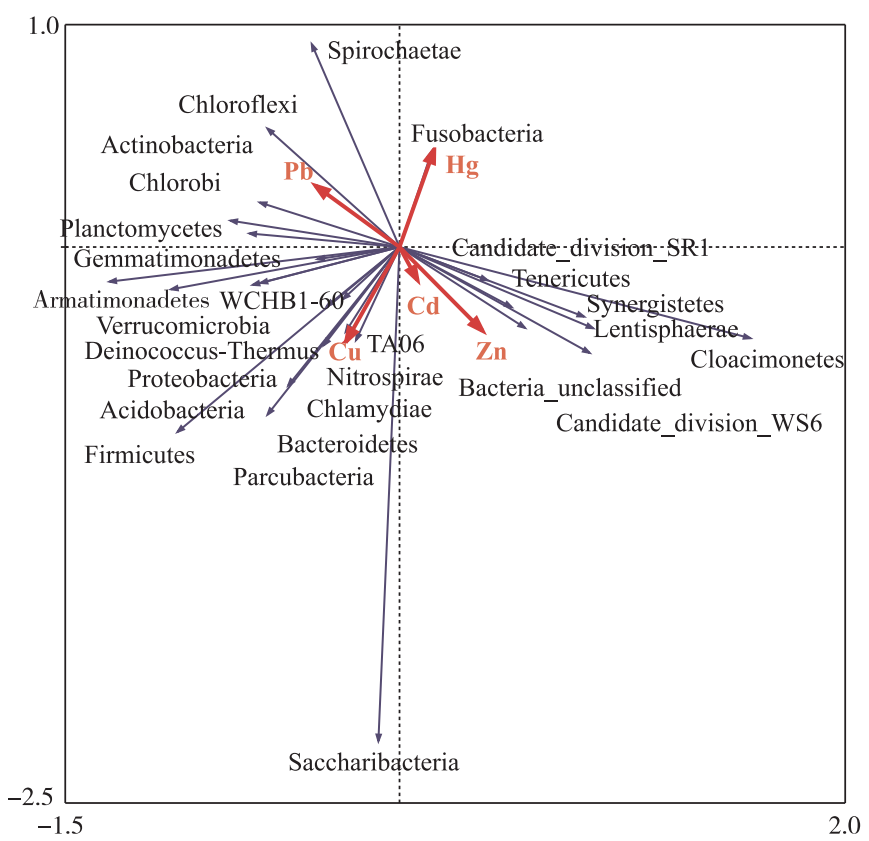

图 5 圥余分析

Fig.5 RDA analysis

\section{3 讨论}

\section{1 鄱阳湖河湖交错带微生物群落结构组成}

本文通过 Miseq 平台测序发现鄱阳湖河湖交错带水体中微生物类群主要为变形菌门、放线菌门、拟杆菌 
门、病微菌门,除了以上 4 种优势菌门还有 Saccharibacteria、厚壁菌门、绿弯菌门、Cloacimonetes、梭杆菌门、硝 化螺旋菌门. 李璐等 ${ }^{[9]}$ 利用分子生物学方法发现,巴丹吉林沙漠盐湖水体中主要细菌门类为 $\gamma$-变形菌亚门、 拟杆菌门、 $\alpha$-变形菌亚门、厚壁菌门和疮微菌门. 任丽娟等 ${ }^{[10]}$ 发现在湖泊水体中, 典型的淡水细菌门类有 21 种, 其中最主要的门类为变形菌门、蓝细菌门、拟杆菌门、放线菌门和疮微菌门. 杜瑞芳等 ${ }^{[11]}$ 运用 PCR-DGGE 技术发现乌梁素海湖滨湿地微生物群落中, 优势菌门为变形菌门,相对丰度达 $78.6 \%$, 其中 $\varepsilon$ 变形菌纲为优 势亚群. 这说明变形菌门在湖泊中分布最广泛, 对不同的生态环境的耐受力较高. 吴兰等 ${ }^{[12]}$ 和江玉梅等 ${ }^{[13]}$ 都发现鄱阳湖水体和底泥沉积物中相对丰度最高的是变形菌门. 本研究也发现了类似的结论.

\section{2 重金属污染特征}

鄱阳湖河湖交错带 $\mathrm{Pb}$ 和 $\mathrm{Hg}$ 污染比较严重 (表 2), 究其原因, 主要是河流上游的有色金属矿的开采与 冶炼等人类活动影响. 而已有的相关研究结果发现鄱阳湖水环境 $\mathrm{Cu}$ 污染严重,如万金保等 ${ }^{[14]}$ 发现乐安河 上游德兴铜矿、有色金属冶炼厂、化工厂等使下游水体、底泥和水生生物出现不同程度的 $\mathrm{Cu} 、 \mathrm{~Pb} 、 \mathrm{Zn}$ 污染; 张 杰等 ${ }^{[15]}$ 利用地累积指数法、潜在生态危害指数法和生态毒性效应等评价方法分析发现, 鄱阳湖主要人湖口 水体重金属污染程度顺序为 $\mathrm{Cu}>\mathrm{Zn}>\mathrm{Pb}>\mathrm{Cd}$; 刘惠民 ${ }^{[16]}$ 在研究鄱阳湖水环境重金属污染中发现, 重金属 $(\mathrm{Cu}$ 、 $\mathrm{Zn} 、 \mathrm{~Pb} 、 \mathrm{Cd})$ 浓度基本都超过国家标准. 本研究与已有研究结果的差异, 主要是研究方法、研究区域及研究时 间等的差异导致的, 深层原因则需要通过进一步采样研究. 鄱阳湖的水质受五河流域的影响非常大, 而河湖 交错带同时受河流与湖泊双重影响, 环境梯度大、微生物多样性丰富、初级生产力和次级生产力较高, 是污 染的缓冲区和净化区, 因此, 研究该区域的微生物群落与重金属污染之间的关系, 为鄱阳湖流域重金属修复 与治理实践提供了良好的理论与技术保障.

\section{3 重金属对微生物多样性的影响}

近几年来,湖泊水体重金属污染日益成为湖泊研究的焦点,而重金属污染与环境微生物之间的相互关 系研究则是重中之重. 有研究表明微生物群落多样性明显受重金属污染的影响, 而不同微生物类群对重金 属的耐受程度不同 ${ }^{[7-8]}$; 重金属 $\mathrm{Cu} 、 \mathrm{Zn} 、 \mathrm{~Pb} 、 \mathrm{Cd}$ 与微生物生物量都呈负相关 ${ }^{[17]}$, 重金属污染影响了微生物细 胞代谢等功能,使其多样性下降; 尹华群也认为, 通常污染程度较高的环境下微生物群落的丰度往往较 低 ${ }^{[18]}$, 即污染越严重导致微生物多样性越低. 本研究中, G8 点位的污染程度较高, 导致该点位微生物多样性 也低. 但 R9 和 H11 点位重金属浓度都较高, 而微生物多样性却较高 (表 2 和表 3 ). Feris 等 ${ }^{[19]}$ 研究表明,在 特定的环境中, 微生物多样性并不是随单一因子的改变而改变的, 而是两个或两个以上的因子共同作用的 结果, 如 $\mathrm{pH} 、 \mathrm{TOC} 、 \mathrm{COD} 、 \mathrm{TP} 、 \mathrm{TN}$ 等. N3、N4 点位 $\mathrm{Hg}$ 污染最严重, 微生物多样性指数有明显的下降. N2、W6 点 位的微生物多样性最低, 从表 2 可以看出两点位的重金属污染都比较严重. 总的来说, 重金属污染一定程度 上会导致微生物多样性的下降,但二者不是简单的线性关系,还受到其他因素的影响.

\section{4 重金属对微生物群落结构的影响}

在特定的环境内, 微生物的群落结构组成易受到周围环境变量的影响, 如营养物循环、重金属浓度变化 等 ${ }^{[20-21]}$. 本研究通过分析重金属浓度与微生物门水平相对丰度之间的相关关系发现, 重金属对微生物群落 结构的影响非常强烈. 有研究表明不同微生物对重金属污染的耐受力不同 ${ }^{[22]}$, 本研究通过几余分析 (图 5) 也得到类似结论. 变形菌门在本研究中各个样点微生物群落结构中所占比例都最大, 这说明变形菌门对重 金属污染的耐受力非常强. Frazar 等 ${ }^{[23]}$ 与 Gillan 等 ${ }^{[24]}$ 的研究也得出了类似的结论. 变形菌门是细菌中最大 的门, 为革兰氏阴性菌, 研究发现革兰氏阴性菌对 $\mathrm{Cu} 、 \mathrm{Zn} 、 \mathrm{~Pb} 、 \mathrm{Cd} 、 \mathrm{Hg}$ 都有一定的耐受力, 其中对 $\mathrm{Cu}$ 的耐受 力较强 ${ }^{[25]} . \mathrm{N} 4$ 和 W5 点位的 $\mathrm{Hg} 、 \mathrm{Zn} 、 \mathrm{Cd}$ 浓度明显高于 $\mathrm{G} 8 、 \mathrm{~N} 1$ 点位, 而放线菌门的相对丰度却远低于 $\mathrm{G} 8 、 \mathrm{~N} 1$ 点位, 这说明放线菌门对 $\mathrm{Hg} 、 \mathrm{Zn} 、 \mathrm{Cd}$ 的耐受力比较低, $\mathrm{Hg} 、 \mathrm{Zn} 、 \mathrm{Cd}$ 一定程度上对放线菌门的生长具有抑制 作用.

\section{4 结论}

1) 鄱阳湖河湖交错带表层水体的 $\mathrm{Pb} 、 \mathrm{Hg}$ 浓度为 $\mathrm{V}$ 类和 $\mathrm{IV}$ 类标准, 污染严重, 而 $\mathrm{Cu} 、 \mathrm{Zn} 、 \mathrm{Cd}$ 均为 II 类标 准. R9、H11 点位污染最严重, 尤其是 H11 点位. $\mathrm{R} 9$ 点位位于乐安河, 其上游重金属矿是导致污染严重的一 个重要因素, H11 点位位于湖口县, 其钢铁冶炼等高污染产业是重要原因. 
2) 鄱阳湖河湖交错带水体微生物群落主要为: 变形菌门 (平均含量为 $58.31 \%$ )、放线菌门 (平均含量为 $13.63 \%$ ) 、拟杆菌门(平均含量为 $9.69 \%$ ) 和疮微菌门 (平均含量为 $1.33 \%$ ).

3 ) 变形菌门对重金属污染的耐受力很强. Hg、Zn、Cd 对放线菌有一定的抑制作用.

4 ) 重金属污染较严重的 R9、H11 点位, 微生物多样性却非常高, 说明重金属污染对微生物多样性的影 响不仅仅随单一因子的变化而变化,而是受多种因子共同作用.

\section{5 参考文献}

[ 1 ] Huang X, Hu B, Wang P et al. Microbial diversity in lake-river ecotone of Poyang Lake, China. Environ Earth Sci, 2016, 75: 965. DOI: 10.1007/s12665-016-5473-0.

[ 2 ] Rader RB, Belk MC, Hotchkiss R et al. The stream-lake ecotone: Potential habitat for juvenile endangered June suckers (Chasmistes liorus). Western North American Naturalist, 2010, 70(4) : 553-561. DOI: 10.3398/064.070.0415

[ 3 ] Yang SQ, Hao RX, Wu F et al. Characteristics of distribution of soil microorganisms in Dexing Copper Ore Deposit. Acta Scientiarum Naturalium Universitatis Pekinensis, 2016, 52(2) : 287-294. DOI: 10.13209/j.0479-8023.2015.110. [杨诗 琴, 郝瑞霞, 吴泮等. 德兴铜矿地区土壤微生物的分布特征研究. 北京大学学报: 自然科学版, 2016, 52(2): 287-294.]

[ 4 ] Wang F, Huang YZ, Wang XL et al. Ecological risk assessment of heavy metals in surrounding soils of tungsten ores: Comparison of different evaluation methods. Environmental Chemistry, 2015, 34(2): 225-233. [王斐, 黄益宗, 王小玲 等. 江西铇矿周边土壤重金属生态风险评价: 不同评价方法的比较. 环境化学, 2015, 34(2): 225-233.]

[ 5 ] Chen SH, Sun TH, Zhou QX et al. Interaction between microorganisms and heavy metals and its application. Chinese Journal of Applied Ecology, 2002, 13(2) : 239-242. DOI: 10.13287/j.1001-9332.2002.0056. [陈素华, 孙铁珩, 周启星 等. 微生物与重金属间的相互作用及其应用研究. 应用生态学报, 2002, 13(2) : 239-242.]

[6] Zhang Y, Cui XY, Luo W. Effects of heavy metal pollutions on the ecological functions of soil microbes: A review. Asian Journal of Ecotoxicology, 2010, 5(3): 305-313. [张妍, 崔骁勇, 罗维. 重金属污染对土壤微生物生态功能的影响. 生态毒理学报, 2010,5(3): 305-313.]

[ 7 ] Liu JX, Li C, Jing JH et al. Composition and environmental adaptation of microbial community in Shibahe Copper Tailing in Zhongtiao Mountain in Shanxi. Environmental Science, 2017, 38(1): 318-326. DOI: 10.13227/j.hjkx. 201606201. [刘晋仙, 李軞, 景炬辉等. 中条山十八河铜尾矿库微生物群落组成与环境适应性. 环境科学, 2017, 38(1): 318-326.]

[ 8 ] Zhao J, Zhao X, Chao L et al. Diversity change of microbial communities responding to zinc and arsenic pollution in a river of northeastern China. Journal of Zhejiang University-Science B: Biomedicine \& Biotechnology, 2014, 15(7) : 670-680. DOI: $10.1631 /$ jzus.B1400003.

[ 9 ] Li L, Hao CB, Wang LH et al. Microbial diversity of salt lakes in Badain Jaran desert. Acta Microbiologica Sinica, 2015, 55(4) : 412-424. [李璐, 郝春博, 王丽华等. 巴丹吉林沙漠盐湖微生物多样性. 微生物学报, 2015, 55(4): 412-424.]

[10] Ren LJ, He D, Xing P et al. Bacterial diversity and ecological function in lake water bodies. Biodiversity Science, 2013, 21(4) : 421-432. DOI: 10.3724/SP.J.1003.2013.12052. [任丽娟, 何聑, 邢鹏等. 湖泊水体细菌多样性及其生态功 能研究进展. 生物多样性, 2013, 21(4): 421-432.]

[11] Du RF, Li JY, Zhao J. Bacterial diversity in littoral wetland of Wuliangsuhai lake. Acta Microbiologica Sinica, 2014,54 (10) : 1116-1128. [ 杜瑞芳, 李靖宇, 赵吉. 乌梁素海湖滨湿地细菌群落结构多样性. 微生物学报, 2014, 54(10): 1116-1128.]

[12] Wu L, Ge G, Gong SJ et al. Composition of bacterial community in the Lao Ye Miao Area of Lake Poyang. Resources and Environment in the Yangtze Basin, 2011, 20(8): 963-969. [吴兰, 葛刚, 龚世杰等. 鄱阳湖老爷庙水域细菌群落组 成分析. 长江流域资源与环境, 2011, 20(8): 963-969.]

[13] Jiang YM, Zhang C, Huang XL et al. Effect of heavy metals in the sediment of Poyang Lake estuary on microbial communities structure base on Mi-seq sequencing. China Environmental Science, 2016, 36(11): 3475-3486. [江玉梅, 张晨, 黄 小兰等. 重金属污染对鄱阳湖底泥微生物群落结构的影响. 中国环境科学, 2016, 36(11): 3475-3486.]

[14] Wang JB, Yan WW, Xie T. Research on heavy metals pollution status of Le'an River, Lake Poyang Basin. J Lake Sci, 
2007, 19(4) : 421-427. DOI: 10.18307/2007.0410. [万金保, 间伟伟, 谢婷. 鄱阳湖流域乐安河重金属污染水平. 湖泊科学, 2007, 19(4): 421-427.]

[15] Zhang J, Chen X, Liu QC et al. Distribution and potential risk assessment of heavy metals in the main estuaries of Lake Poyang's tributaries. Resources and Environment in the Yangtze Basin, 2014, 23 (1) : 95-100. DOI: 10.11870/cjlyzyyhj201401014. [张杰, 陈熙, 刘倩纯等. 鄱阳湖主要人湖口重金属的分布及潜在风险评价. 长江流域资源与环境, 2014, 23(1) : 95-100.]

[16] Liu HM. Research on heavy metals pollution in water environment of Poyang Lake. Environment Science and Technology, 1990，(1)：1-5. [刘惠民. 鄱阳湖水环境重金属污染研究. 环境科学与技术，1990，(1)：1-5.]

[17] Wang XL, Xu JM, Yao HY et al. Effects of $\mathrm{Cu}, \mathrm{Zn}, \mathrm{Cd}$ and $\mathrm{Pb}$ compound contamination on soil microbial community. Acta Scientiae Circumstantiae, 2003, 23(1): 22-27. DOI: 10.13671/j.hjkxxb.2003.01.005. [王秀丽, 徐建民, 姚槐应 等. 重金属铜、锌、镉、铅复合污染对土壤环境微生物群落的影响. 环境科学学报, 2003, 23(1): 22-27.]

[18] Yin HQ. Development and application of the microarray technology during the research on the structure and function of microbial communities for acid mine drainages from the copper mines [Dissertation]. Changsha: Central South University, 2007: 35-37. [尹华群. 在铜矿矿坑水微生物群落结构与功能研究中基因芯片技术的发展与应用 [学位论文]. 长 沙: 中南大学, 2007: 35-37.]

[19] Feris K, Ramsey P, Frazar C et al. Differences in hyporheic-zone microbial community structure along a heavy-metal contamination gradient. Applied and Environ-mental Microbiology, 2003, 69(9) : 563-5573. DOI : 10.1128/AEM.69.9.55635573.2003.

[20] Liao PC, Huang BH, Huang S. Microbial community composition of the Danshui river estuary of Northern Tai-wan and the practicality of the phylogenetic method in microbial barcoding. Microbial Ecology, 2007, 54 (3) : 497-507. DOI: 10. 1007/s00248-007-9217-2.

[21] Simmons MP. Independence of alignment and tree search. Molecular Phylogenetics and Evolution, 2004, 31(3) : 874-879. DOI: $10.1016 /$ j.ympev.2003.10.008.

[22] Prasad MNV. Metals in the environment: Analysis by biodiversity. Journal of Organometallic Chemistry, 2003, 669( 1 ) : 207-207.

[23] Frazar C, Gannon JE, Ramsey P et al. Differences in hyporheiczone microbial community structure along a heavy-metal contamination gradient. Applied Environmental Microbiology, 2003, 69: 5563-5573. DOI: 10.1128/AEM. 69.9.55635573.2003.

[24] Gillan DC, Danis B, Pernet P et al. Structure of sediment associated microbial communities along a heavy-metal contamination gradient in the marine environment. Applied Environmental Microbiology, 2005, 71(2) : 679-690. DOI: 10.1128/ AEM.71.2.679-690.2005.

[25] Matyar F. Antibiotic and heavy metal resistance in bacteria isolated from the Eastern Mediterranean Sea coast. Bull Environ Contam Toxicol, 2012, 89: 551-556. 